\title{
DO JOGO E DO LÚDICO NO ENSINO DA EDUCAÇÃO FÍSICA ESCOLAR
}

Recebido em: 25/08/2009

Aceito em: 14/12/2009

José Pereira de Melo ${ }^{1}$

Universidade Federal do Rio Grande do Norte - Departamento de Educação Física Natal - Rio Grande do Norte - Brasil

João Carlos Neves de Souza e Nunes Dias ${ }^{2}$

Universidade Federal de Alagoas - Curso de Educação Física Maceió - Alagoas - Brasil

RESUMO: Compreendendo o jogo como fenômeno da cultura e como conteúdo da Educação Física escolar, a partir da Cultura de Movimento, direcionamos nossa reflexão na relação entre jogo e lúdico. No sentido de evidenciar aproximações e distanciamentos, destacamos o esporte moderno como um ponto de tensão dessa relação, que resignifica o sentido do jogo e sua relação com o lúdico.

PALAVRAS CHAVES: Educação Física e Treinamento. Educação. Cultura. Atividades de lazer.

\section{THE PLAY AND THE PLAYFULL IN THE TEACHING OF PHYSICAL EDUCATION AT SCHOOL}

ABSTRACT: Understanding the game as culture phenomenon and as the content of Physical Education at school, from the Movement Culture, direct our reflection on the relationship between play and playfulness. In order to highlight similarities and differences, we highlight the modern sport as a point of tension of this relationship, which reframes the meaning of the play and its relationship with the playful.

\footnotetext{
${ }^{1}$ Doutor em Educação Física pela Universidade Estadual de Campinas (1998). Professor Associado I e docente do curso de Educação Física (DEF) da Universidade Federal do Rio Grande do Norte. Coordenador do Núcleo de Formação continuada para professores de Artes e Educação Física - Paidéia. Coordenador do Grupo de Pesquisa Corpo e Cultura de Movimento. Professor do programa de PósGraduação em Educação da Universidade Federal do Rio Grande do Norte.

${ }^{2}$ Mestre em Ciências Sociais (2007) pela Universidade Federal do Rio Grande do Norte. Professor Assistente I e docente do curso de Educação Física (Centro de Educação) da Universidade Federal de Alagoas. Pesquisador do Grupo de Pesquisa Corpo e Cultura de Movimento (UFRN) e do Grupo de Estudo e Pesquisa em Docência e Formação Profissional em Educação Física (UFAL).
} 
KEYWORDS: Physical Education and Training. Education. Culture. Leisure Activities

\section{NOTAS SOBRE O JOGO E O LÚDICO}

É enquanto fenômeno da cultura que compreendemos a configuração do jogo. Nesse sentido o argumento de Huizinga nos ajuda a pensar o jogo enquanto fenômeno cultural que "transcende as necessidades imediatas da vida" (HUIZINGA, 1990, p. 04). Não se restringe, portanto, a uma relação fisiológica do organismo, pois todo jogo possui uma ação significante. Todo jogo está revestido de um significado construído e amplificado pela cultura, materializado na diversidade de sua objetivação social, que se revela e se esconde a partir do sentido e do significado que cada sociedade lhe atribui.

A criatividade presente no jogo relaciona-se com a possibilidade de flexibilização e manipulação da realidade, não sendo um fenômeno da vida cotidiana. Todo jogo acontece no campo do imaginário, construindo uma nova realidade, acessada e compreendida eminentemente pelos sujeitos que participam de sua ação. Combinando em si as idéias de limites, liberdade e invenção, os jogadores passam a envolver num campo delimitado e imaginário, sendo que sua ação parasita o campo da subjetividade (CALLOIS, 1990).

Sua dinâmica é desenvolvida a partir de regras explícitas a todos os participantes do jogo. Absorvendo inteiramente o jogador, desenvolve-se a partir de regras continuamente (re) organizadas na relação entre os jogadores. O sujeito, portanto, flexibiliza as regras do jogo a partir de "acordos" estabelecido entre os jogadores. É na tensão e incerteza que as ações dos jogadores se desenvolvem. A ação do jogo revela o próprio jogo, tendo um fim em si mesmo, sua finalidade está no próprio ato de jogar. No 
jogo os sujeitos participam gratuitamente, sem sofrerem coação externa, enfatizando-se a liberdade em sua ação (HUIZINGA, 1990).

Suspenso da realidade corrente, de uma lógica racionalista e utilitarista, o jogo está impregnado de desejos individuais e de significações culturais, ou seja, coletivas e sociais. Se pudéssemos considerar do ponto de vista lógico, há dificuldades em realizar deduções do jogo, no sentido de garantir a operacionalização predeterminada de ações racionalistas na realização do jogo, pois o jogo se realiza no campo do imaginário, potencializado pelo lúdico compreendido a partir de uma racionalidade sensível. A compreensão do lúdico coloca-se, nessa compreensão, como um elemento transgressor, na medida em que nos provoca a atitude de voltar ao cogito e procurar ali um Logos mais fundamental do que o pensamento objetivo, que lhe dê seu direito relativo e, ao mesmo tempo, o coloque em seu lugar (MERLEAU-PONTY, 1999, p. 489).

A racionalidade sensível é um desafio à análise objetivista da ciência, à argumentação lógica, ao utilitarismo técnico, pois o conhecimento sensível opera pela incerteza, pela imprevisibilidade, está aberto à configuração de novas possibilidades de construção da realidade. Nesse contexto, o lúdico pode ser compreendido como um operador da imaginação, do sonho e da criatividade como dimensões do humano.

Entre outros lugares da criação humana, compreendemos que o lúdico se expressa com vigor no jogo, ou ainda, atravessa toda a compreensão de jogo, sendo um caminho para que possamos perceber potencialidade da dimensão humana da inventividade. Compreendemos, portanto, que a intencionalidade do jogo não se inscreve em uma lógica linear, mas a partir de uma racionalidade sensível, em que o lúdico é sua natureza ontológica e epistêmica. 


\section{DO JOGO E DO ESPORTE: APROXIMAÇÕES E DISTANCIAMENTOS}

Comumente nas intervenções pedagógicas da Educação Física escolar em que o jogo é elencado como conteúdo a ser trabalhado, é possível observar aproximações com o conteúdo do esporte. No sentido de provocar algumas reflexões sobre essa relação, partimos de três pressupostos: a hegemonia do esporte nas aulas de Educação Física; as possibilidades da relação entre jogo e esporte que tem sido construído historicamente na Educação Física escolar; e a reinvenção do jogo como fenômeno do lúdico.

No início de nossos argumentos, apresentamos algumas considerações sobre o jogo que, em síntese, compreendemos tendo como sua natureza ontológica e epistêmica a dimensão do lúdico. O lúdico tece, portanto, o jogo. O lúdico é o estofo do jogo. A partir dessa afirmativa, podemos nos perguntar sobre o esporte moderno. Quais suas características? Como tem se constituído historicamente?

Não pretendemos realizar uma exegese do conceito de esporte moderno a partir dos diferentes autores que tem contribuído para o debate em torno de sua caracterização seja a partir de pesquisas históricas ou sociológicas do esporte. Para nossa reflexão é suficiente, nesse momento, evidenciarmos algumas características centrais do esporte moderno, a partir de alguns lugares de consenso.

Para pensar no esporte é preciso contextualizá-lo do ponto de vista histórico e social, como uma produção humana, fortemente marcada pelo período moderno, principalmente a partir do século XIX (LUCENA, 2001; MELO, 1999; BRACHT, 2003; ELIAS \& DUNNING, 1992). O esporte moderno tem marcas da lógica da urbanização e da industrialização que caracterizaram fortemente o século XIX, que tanto pode ser percebido como um processo da esportivização das ações lúdicas pelas elites (LUCENA, 2001), como também a partir da esportivização de jogos das classes 
populares ingleses pela aristocracia da época (BRACHT, 2003). Nesse sentido, podemos afirmar uma primeira característica na gênese do esporte, "uma ação 'nova' e própria de uma sociedade em transformação. É considerado, pelas elites, como uma prática 'civilizada', por isso educada e educativa, em contraposição aos jogos tradicionais vistos como parte de uma sociedade colonial e arcaica, fontes de emergência de atitudes rudes e primitivas" (LUCENA, 2001, p.11).

Destacamos ainda características como a competição; a busca do rendimento físico-técnico; objetificação do recorde; a racionalização e cientifização do treinamento dos movimentos; secularização; especialização dos papéis; operacionalização burocrática de funcionamento; quantificando dos resultados; controle minucioso da gestualidade do corpo (BRACHT, 2003).

Essas caracterizações do esporte moderno distanciam-se da compreensão do jogo como lugar de expressão do lúdico. No entanto, é comum no dia-a-dia percebermos certa confusão, ou ainda, uma associação na compreensão entre jogo e esporte. Considerando que são fenômenos sócio-culturais próximos e distantes, de que forma podemos articular o jogo ao esporte, sem que haja uma descaracterização do primeiro em detrimento do segundo, ou vice-versa?

Quando as questões são colocadas, nos é exigido posturas e decisões frente ao que é questionado. Ao contrário de uma perspectiva que tente esgotar o assunto, procuramos pensá-las enquanto potencialidades. É assim que passamos a algumas considerações sobre a relação entre jogo e esporte, tendo como foco a Educação Física escolar.

A temática do jogo e do esporte se faz presente na área de maneira significativa, geralmente ligada ao desenvolvimento humano, a psicomotricidade, à crítica da 
especialização precoce. Particularmente, os textos e a intervenção do professor João Batista Freire tem alimentado essas reflexões, e apontado possibilidades de intervenção pedagógica na área da Educação Física escolar. Não pretendemos realizar uma análise das idéias presentes em suas obras. Mas gostaríamos de destacar uma proposição interessante que vem sendo divulgada na área da Educação Física, e ao refletir sobre ela, pensarmos possibilidades sobre a articulação entre o jogo e o esporte.

Em um texto intitulado Da criança, do brinquedo e do esporte ${ }^{3}$, o professor João Batista Freire (1992), reflete sobre a pedagogia do esporte, afirmando ser o jogo, compreendido como brinquedo infantil, o esporte em crisálida, sendo, portanto, de complexidade, a diferença entre jogo e esporte. Aqui, a noção de complexidade aproxima-se da afirmativa cartesiana em operar do mais simples para o mais complexo.

Para o autor, o jogo seria como um estágio, um momento passageiro, como uma crisálida a desabrochar, portanto, o esporte estaria como que latente no jogo. Senão vejamos: "Se, como afirmamos pouco antes, o brinquedo da criança é o esporte em crisálida, o esporte é o brinquedo de gente grande" (FREIRE, 1992, p.305). De certo modo, nessa perspectiva, no jogo estariam os elementos do esporte. O jogo seria uma fase, um estágio, um momento, para o desabrochar do esporte. Alimentados pela provocação de Benjamin (2002), perguntamo-nos se essa perspectiva apontada por Freire (1992) seria uma sensibilidade do adulto na compreensão do universo infantil? Não haveria nessa afirmação de João Batista Freire (1992) uma perspectiva instrumental da infância e do lúdico na cultura infantil? Seria o caso de uma captura da cultura infantil e, através de uma determinada educação dos gestos, chegar ao esporte? Vislumbrar na criança o adulto?

\footnotetext{
${ }^{3}$ O título e a proposta desse texto é uma analogia ao texto de Walter Benjamin (2002), intitulado: Reflexões sobre a criança, o brinquedo e a educação.
} 
Compreendemos que a criança, "não é um adulto em miniatura, com uma consciência semelhante à do adulto, porém inacabada, imperfeita - essa idéia é puramente negativa. A criança possui outro equilíbrio, e é preciso tratar a consciência infantil como um fenômeno positivo" (MERLEAU-PONTY ${ }^{4}$ citado por NÓBREGA, 2008, p. 13).

Podemos interpretar nessa concepção proposta por Freire (1992) certa "higienização" da polissemia de sentidos e significados que o jogo pode provocar. Essa "higienização" compreendida como o estabelecimento de normas, de hábitos, que regulamentam as subjetividades de acordo com modelos padronizados, como é o caso do esporte. Essa "higienização" é potencializada por uma perspectiva de instrumentalização do jogo em detrimento do esporte. Apresentamos essa provocação no sentido de que se tornou lugar comum na área da Educação Física escolar a articulação entre jogo e esporte divulgados a partir da noção de jogos pré-desportivos, ou ainda a partir do termo "jogos lúdicos".

Nesse lugar comum de aproximação entre jogo e esporte, a ênfase está na aprendizagem dos conteúdos esportivos, utilizando-se do estado de brincar presente na cultura infantil. Acreditamos, no entanto, que os brinquedos populares são manifestações da cultura, assim também como o esporte o é, mas não podemos destonalizar o sentido do jogo no esporte, nem destonalizar o esporte no jogo, são manifestações diferentes da Cultura de Movimento, enquanto critério organizador do conhecimento da Educação Física na escola.

Por Cultura de Movimento compreendemos a conceituação integral de objetivações culturais, no qual o movimento humano não se restringe ao deslocamento

\footnotetext{
${ }^{4}$ MERLEAU-PONTY, M. Psicologia e Pedagogia da criança: cursos da Sorbone (1949-1952). São Paulo: Martins Fontes. 569 p.
} 
do corpo no espaço, mas é intermediador simbólico das diferentes culturas, expressando-se nos jogos, lutas, Artes e em outras manifestações histórico e cultural. A Cultura de Movimento inclui e articula o orgânico e o simbólico, ou seja, a natureza do movimento, os processos biofisiológicos, e seus significados, a sua construção histórica e cultural, na ênfase à intencionalidade do movimento (MENDES, 2005; NÓBREGA, 2005).

Diante dessa reflexão, de aproximação e distanciamento entre jogo e esporte, perguntamos: seria possível construir possibilidades pedagógicas em que o lúdico fosse ressaltado não enquanto meio, ou uma simples estratégia para fazer desabrochar o esporte ou minimizar os aspectos de "treinamento" da prática esportiva? É possível operar rupturas na compreensão do esporte a partir do elemento do lúdico?

As problematizações aqui colocadas são no sentido de podermos pensar outras formas de abordagem do jogo nas aulas de Educação Física, como uma possibilidade de minimizar a hegemonia da perspectiva do esporte a partir de um modelo de rendimento nas aulas de Educação Física escolar, ressaltando o lúdico enquanto característica fundamental do jogo. Portanto, não se trata de uma perspectiva, digamos, "purista", "idealista", ou ainda "tradicional", na compreensão do jogo. Como se o jogo fosse um campo sistêmico e fechado a possíveis relações ou reinvenções. Compreensão que não se aplica à dinâmica dos fenômenos sociais. No entanto, a partir dessas reflexões a pretensão é a de evidenciar, compreender e valorizar o lúdico enquanto dimensão humana. Pois, no campo das práticas corporais, é evidente a hegemonia do modelo esportivo, frente à diversidade de práticas corporais existentes, dentre elas a polissemia dos jogos. 
Como um contraponto aos jogos pré-desportivos, tem circulado na área da Educação Física uma produção significativa em torno dos jogos cooperativos. Um dos principais divulgadores dessa perspectiva tem sido Fábio Broto (1997). Nesses jogos, a ênfase não está na competição, mas na cooperação entre os sujeitos que realizam as atividades. Joga-se com o outro, portanto, com parceiros e não com adversários. O jogo está aberto para a convivência com as diferenças, bem como na criatividade para o desenvolvimento das ações. A democratização da participação nos jogos, bem como o sentimento de coletividade são pilares fundamentais dos jogos cooperativos (BROTO, 1997).

\section{DO LÚDICO COMO CRIAÇÃO E A REINVENÇÃO DO JOGO}

É no sentido de alimentar espaços que possibilitem a emergência do lúdico, que vislumbramos os jogos como conteúdo da Educação Física escolar. Mais do que a tentativa de concluir qualquer problemática colocada durante o texto, pretendemos provocar a reflexão e o debate em torno da compreensão do lúdico enquanto dimensão humana. Nesse sentido, Manoel de Barros nos provoca a desinventar objetos. "O pente, por exemplo. Dar ao pente funções de não pentear. Até que ele fique à disposição de ser uma begônia. Ou uma gravanha. Usar algumas palavras que ainda não tenham idioma" (BARROS, 2004, p. 11). A poesia, enquanto metáfora pode nos ajudar a pensar numa relação de cumplicidade entre o jogo e o lúdico que potencialmente podem ser operadas nas aulas de Educação Física escolar.

\section{REFERENCIAS}

BARROS, M. O livro das ignorãças. Rio de Janeiro: Record, 2004. 104 p. 
BENJAMIN, W.. Reflexões sobre a criança, o brinquedo e a educação. 5. ed. São Paulo: Editora 34, 2002. 176 p.

BRACHT, V. Sociologia crítica do esporte: uma introdução. 2. ed. Ijuí: Ed. Unijuí, 2003. $134 \mathrm{p}$.

BROTTO, F. O. Jogos cooperativos: se o importante é competir, o fundamental é cooperar! 7. ed. Santos: Ed. Re-Novada, 1997. 170 p.

CALLOIS, R. Os jogos e os homens: a máscara e a vertigem. Lisboa: Cotovia, 1990. $228 \mathrm{p}$.

ELIAS, N.; DUNNING, E. A busca da excitação. Lisboa: Difel, 1992. 421 p.

FREIRE, J. B. Da criança do brinquedo e do esporte. Revista Brasileira de Ciências do Esporte, v. 02, n. 13, p. 299-307, 1992.

HUIZINGA, J. Homo-ludens: o jogo como elemento da cultura. 2. ed. São Paulo: Perspectiva, 1990. 256 p.

LUCENA, R. O esporte na cidade: aspectos do esforço civilizador brasileiro. Campinas: Autores Associados, 2001. 153 p.

MELO, V. A. História da educação física e do esporte no Brasil. São Paulo: IBRASA, 1999. $115 \mathrm{p}$.

MENDES, Maria Isabel Brandão de Souza. O conhecimento do corpo na Educação Física escolar. In NÓBREGA, Terezinha Petrucia (Org). O ensino de Educação Física de $5^{\mathbf{a}}$ a $8^{\mathbf{a}}$ série. 2005. p. 70-79.

NÓBREGA, Terezinha Petrucia. O mundo vivido e a cultura elaborada: processos de conhecimento na Educação Física escolar. In NÓBREGA, Terezinha Petrucia (Org). O ensino de Educação Física de $5^{\mathbf{a}}$ a $8^{\mathbf{a}}$ série. 2005. p. 83-90.

De quantos anos precisa um artista para poder falar com sua própria voz? Notas, memórias e experiências com a educação de crianças. In: CAPISTRANO, N. J.; PONTES, G. (Org.). O ensino de educação física e artes na infância. Coleção Cotidiano Escolar, v. 4, n. 1, p. 09-23, Natal: Paidéia, 2008.

MERLEAU-PONTY, M. Fenomenologia da percepção. 2. ed. São Paulo: Martins Fontes, 1999. 662 p.

\section{Endereço dos Autores:}

João Carlos Neves de Souza e Nunes Dias

Rua Deputado José Lages, 1230.

Edifício Rios do Éden. Bloco Pizon. Apt. 503.

Maceió/ Alagoas. CEP: 57035-330.

Endereço Eletrônico: j80dias@yahoo.com.br 